\title{
MULTI-CRITERIA DECISION ANALYSIS TECHNIQUES APPLIED TO THE CONSTRUCTION OF A COMPOSITE BOX-GIRDER BRIDGE
}

\author{
V. Yepes, D. Martínez-Muñoz, N. Ata-Ali, J.V. Martí \\ ICITECH. Dept. Ingeniería de la Construcción y Proyectos de Ingeniería Civil. Universitat \\ Politècnica de València (SPAIN)
}

\begin{abstract}
This work is based on the case study of a multiple-criteria decision analysis, aimed for the students of the Predictive and optimization models for concrete structures subject, which is taught in the master's degree in Concrete Engineering at the Universitat Politècnica de València. This course features different blocks, among which the optimization of structural and constructive elements by different techniques stands out. Additionally, different techniques of multiple-criteria decision analysis are studied. This case study allows the comparison between two different evaluation methods; the direct comparison method SAW, and the pairwise comparison method AHP. The object of this study is to carry out an analysis of the different types of structural alternatives of a bridge. In this case, four possibilities are considered: Lower Arch, bowstring, cable-stayed and box-girder bridges; for a span length of $100 \mathrm{~m}$, without any supports due to the environmental conditions. The student will acquire different competencies that will allow him, not only to obtain the technical knowledge, but also the capacity to analyze, and solve problems, creativity, innovation, as well as an ethical, professional and environmental awareness. The result of this article opens a field for the investigation of these type of processes through other methods of multiple-criteria decision analysis.
\end{abstract}

Keywords: multi-criteria, decision making, composite structures, steel-concrete, construction, bridge, postgraduate education, structural design.

\section{INTRODUCTION}

\subsection{Postgraduate studies in the engineering field}

Training and education in engineering is a fundamental part of the development of any country. Taking courses and postgraduate Master's helps the students to obtain the necessary knowledge to be able to specialize in a specific scientific field. In Spain there are many universities that offer various masters and courses. The Universitat Politècnica de València, offers several of them among which is the Master's Degree in Concrete Engineering. It has the EUR-ACE International Seal of Excellence, which certifies that these studies have a broad compliance with the professional requirements of engineering. The purpose is to perform a work within the field of "Predictive and optimization models for concrete structures" where our team of researchers has developed different works [1-12].

\subsection{Background}

For years, construction projects have had a very high magnitude and complexity that require specialized engineers with more experience. In addition, these designs must have the quality of being sustainable, a concept that is now booming, defined as the "Development that meets the needs of the present without compromising the ability of future generations to meet their own needs" [13]. With this long-term vision, the study of the life cycle has become one of the basic tools to be able to make decisions in the design of any construction. It is precisely in this sector, where reaching an agreement between the social, environmental and economic aspect makes possible the sustainability of the design [14-16] to achieve this consensus, the use of decision-making methods is necessary [17-21].

In decision making we find different criteria and different alternatives to choose from [21-24]. These criteria are of different importance and are those who incline us for one alternative or another. To be able to safely take the most appropriate option it is necessary to have a tool that allows us to measure the importance by means of a barometer based on different scales [25, 26].

Making an appropriate decision-making is a complicated task if there are many alternatives and if the criteria used are contradictory [27]. For this purpose, support tools are used to facilitate the choice [20, 28]. These tools are analytical techniques that allow us to determine some weighting factors of the 
criteria that have been considered [29, 30]. Some researchers have developed these methods combining them with others and have developed tools that could be coupled to other organizational and activity needs [31, 32]. In this paper, we are going to focus on two methods for decision making, and with them we will assess which one of the four bridges analyzed is the one that has the greatest possibility to be built in a real sustainable design.

\section{MULTI-CRITERIA DECISION-MAKING METHOD}

Decision making is an action that appears daily, many situations require the need to choose one alternative among others. Commonly, that decision has an easy solution because only it only considers one criterion. But in the professional trajectory of an engineer, the decisions that have to be made carry an important impact, in terms of cost, or environmental and social impact among others. Because of this, the decision-making process takes an important role to assess the different alternatives and decide which one is the most suitable one according to various criteria.

When the problem only depends on one variable, the optimum solution is the one that minimized or maximizes that criteria. Real problems usually have lots of aspects that could be contradictories between them and come into conflict. Problems that take into account more than one criteria are difficult to evaluate directly, because of this, the multi-criteria decision making methods were developed to allow the assessment of a number of alternatives or solutions $A_{j}(i=1,2, \ldots, n)$ based in the score of each alternatives $r_{i j}$ in relation to a number of criteria $C_{i}(j=1,2, \ldots, m)$. The interaction between the solutions and the criteria could be expressed as the decision matrix $M_{m n}$ :

$\mathbf{M}_{\mathrm{mn}}=$\begin{tabular}{c|cccc} 
& $\mathbf{A}_{1}$ & $\mathbf{A}_{2}$ & $\ldots$ & $\mathbf{A}_{\mathbf{n}}$ \\
\hline $\mathbf{C}_{1}$ & $\mathrm{r}_{11}$ & $\mathrm{r}_{12}$ & $\ldots$ & $\mathrm{r}_{1 \mathrm{n}}$ \\
$\mathbf{C}_{2}$ & $\mathrm{r}_{21}$ & $\mathrm{r}_{22}$ & $\ldots$ & $\mathrm{r}_{2 \mathrm{n}}$ \\
$\ldots$ & $\ldots$ & $\ldots$ & $\ldots$ & $\ldots$ \\
$\mathbf{C}_{\mathrm{m}}$ & $\mathrm{r}_{\mathrm{m} 1}$ & $\mathrm{r}_{\mathrm{m} 2}$ & $\ldots$ & $\mathrm{r}_{\mathrm{mn}}$
\end{tabular}

Figure 1. Decision matrix

The punctuations vary depending on the criteria. If the criteria are quantitative (e.g. cost), the value of the punctuation is a number, whereas if it is qualitative (e.g. aesthetic), to assign a value of punctuation is more difficult, usually the alternatives are classified according to an assessment scale. Subsequently, that classification is transformed in numerical values.

We have seen that criteria could be qualitative or quantitative, furthermore, the range of values of the assessment of each criteria could be different. Because of this, the punctuations need to be normalized and the original values $r_{i j}$ are transformed to $r_{i j}^{\prime}$ normalized. Concurrently, the weight $w_{i}$ of the criteria $C_{i}$ depending on the importance of that criteria to the final goal must be obtained. Therefore, the decision matrix, is converted in another matrix before being evaluated, where the initial scores $r_{i j}$ have been in normalized with associated weights $v_{i j}$ :

$$
v_{i j}=w_{i} \cdot r_{i j}^{\prime}
$$

Weights are associated with the relative importance of the criteria to achieve the final score of the solution. The weight allocation is an important factor, because slight variations of these weights could mean a change in the selected alternative. There are a lot of methods for weight assigning, which could be objective or subjective. In this case, two subjective weight assigning method have been used: A direct comparison method and a pairwise comparison one.

\subsection{Direct scoring methods}

Decision makers assign directly the criteria weights, they must rate different criteria considering a scale, usually distributing 100 points between the different criteria assigning them a percentage. These are the simplest methods, based on evaluating the different alternatives through basic arithmetic operations. 
The Simple Additive Weighting (SAW) method is the oldest, it assesses the different alternatives by making the sum of the normalized value of each criterion by its corresponding weight.

\subsubsection{Simple Additive Weighting (SAW)}

This is the simplest and the most used multi-criteria decision-making method. It assesses the different alternatives by making the sum for each alternative $\left(A_{i}\right)$ of the normalized value of each criterion $\left(r_{i j}^{\prime}\right)$ multiplied by its corresponding weight $\left(w_{i}\right)$.

$$
S_{j}=\sum_{i=1}^{m} w_{i} \cdot r_{i j}^{\prime}=\sum_{i=1}^{m} v_{i j}
$$

Once the sum is obtained for all the alternatives, they are compared and ranked with an ascending order. The alternative whose value is the greatest will be the best. The allocation of the relative weight of each criterion is directly assigned by experts. The normalization of an alternative criterion is performed by the division of the criterion value of that alternative between the maximum value of that criterion for all alternatives:

$$
r_{i j}^{\prime}=\frac{r_{i j}}{\max _{j} \cdot r_{i j}}
$$

At first SAW was thought only to maximize criteria that are positive, therefore, it has two limitations that should be taken into account. On the one hand, to normalize the criteria to be minimized, a conversion of this minimization is made by a maximization, so that the normalization of an alternative criterion is made by the division of the minimum value of that criterion for all alternatives between the value of the criterion of that alternative:

$$
r_{i j}^{\prime}=\frac{\min _{j} \cdot r_{i j}}{r_{i j}}
$$

\subsection{Pairwise comparison methods}

Pairwise comparison methods are very useful to obtain the weights of the different criteria and to evaluate subjective criteria by compared the alternatives to each other. The Analytical Hierarchy Process (AHP) method was the first one to be developed, and one of the most used methods in decision making problems.

\subsubsection{Analytical Hierarchy Process (AHP)}

The Analytical Hierarchy Process (AHP) method was the first to be developed by Thomas L. Saaty, which coupled with its simplicity has made it a widely used and popular decision-making method. To this end, a decision-making problem must be structured in a hierarchical way where the final objective is at the highest level, and the criteria and sub-criteria at the lower levels as shown in Fig. 2 it is very important the right choice of criteria and sub-criteria, which must be very well defined, relevant and mutually exclusive.

When defining the hierarchical structure, it should be taken into account that the number of criteria should not be excessive. For example, according to Bahurmoz [25], the number of criteria and subcriteria in each level should not be greater than 7 , in order to avoid an excessive pairing, and Miller [33] says that the number of criteria assimilated by the people is $7 \pm 2$.

After defining the hierarchical structure, the comparison of the criteria of each group of the same hierarchical level is made, and the direct comparison by pairs of the alternatives with respect to the criteria of the lower level. This process will be systematically repeated in ascending direction until the final objective is assessed. These valuations are carried out by means of the fundamental scale proposed by Saaty [26] of Table 1. 


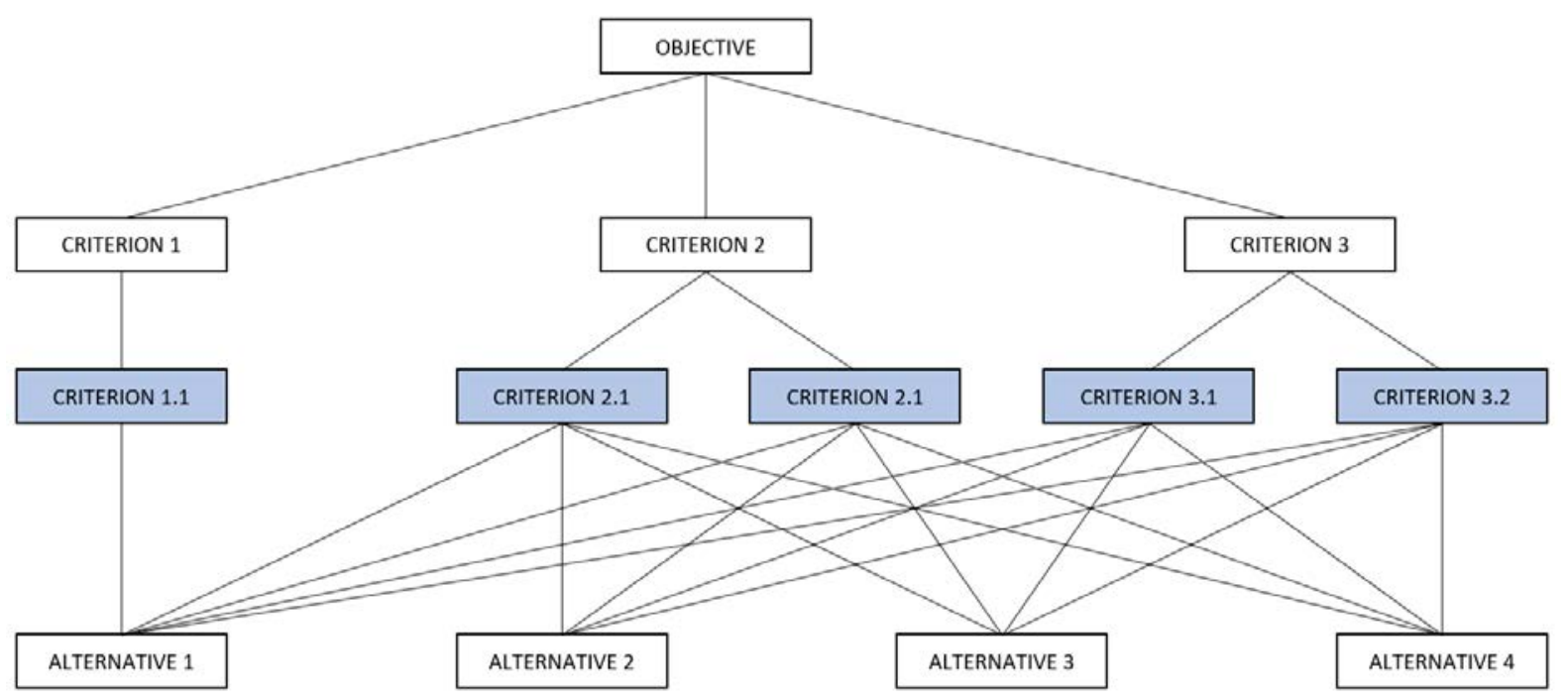

Figure 2. AHP hierarchical structure

Table 1. Saaty Scale

\begin{tabular}{lll}
\hline Intensity & Definition & Explanation \\
\hline 1 & $\begin{array}{l}\text { Equal importance } \\
\text { moderate Importance } \\
\text { of one over another } \\
\text { Essential or strong } \\
\text { importance }\end{array}$ & $\begin{array}{l}\text { Two activities contribute equally to the objective } \\
\text { Experience and judgement strongly favour one activity over another }\end{array}$ \\
$\begin{array}{lll}\text { Very strong } \\
\text { importance }\end{array}$ & $\begin{array}{l}\text { An activity is strongly favoured and its dominance demonstrated in } \\
\text { practice }\end{array}$ \\
9 & Extreme importance & $\begin{array}{l}\text { The evidence favouring one activity over another is of the highest } \\
\text { possible order of affirmation }\end{array}$ \\
$2,4,6,8$ & Intermediate values & When compromise is needed \\
\hline
\end{tabular}

In both, the comparison of the different alternatives to the criterion of the level inferior of the hierarchical structure, as well as the comparison of the different criteria of the same hierarchical level a matrix called the decision matrix is used. Each time an array is generated, the consistency of this is evaluated. This is done to detect contradictions in the valuation of decision makers. This consistency is obtained by the Consistency Index $(\mathrm{Cl})$ where $\lambda_{\max }$ is the maximum eigenvalue and $\mathrm{n}$ is the dimension of the decision matrix. A consistency index equal to 0 means that the consistency is complete. Once the consistency index is obtained, the consistency ratio (CR) is obtained by being accepted as long as it does not exceed $10 \%$.

$$
\begin{gathered}
C I=\frac{\lambda_{\max }-n}{n-1} \\
C R=\frac{C I}{R I}
\end{gathered}
$$

Once the consistency is verified, weights are obtained, which represent the relative importance of each criterion or the priorities of the different alternatives with respect to a certain criterion. To do this, the original AHP uses the method of the eigenvalues, where the following equation must be resolved:

$$
A \cdot w=\lambda_{\max } \cdot w
$$


Where $A$ represents the comparison matrix, $w$ the eigenvector or vector of preference, and $\lambda_{\max }$ the eigenvalue. [34]

\subsection{Problem approach, bridge alternatives and criteria}

The case study is to solve a section of viaduct located in the municipal term of Morella (Castellón, Spain). The track alignment is curved and also has both a longitudinal and transverse slope, furthermore the environmental conditions impose that a $100 \mathrm{~m}$ length span has to be solved without supports.

To solve the problem exposed, the following design alternatives have been proposed: Lower Arch, bowstring, cable-stayed and box-girder bridges. These alternatives have been designed and calculated before in Martínez-Muñoz master's degree in civil engineering's thesis [35].

\subsubsection{Bridge alternatives}

For the $100 \mathrm{~m}$ span length there are three typologies that could be competitive: Arch, cable-stayed and girder bridge. In addition, the construction process must be taken into account, because of the unusual conditions of that structure.

The first alternative is to build a continuous box-girder steel-concrete composite bridge, which requires a constructive process that allows to push the beam along the bridge trace, enabling the deflection to recover when the front part of the beam goes into contact with the stacks. For this, a staying system is designed, it is composed by a steel staying tower that allows workers to increase the stays tension to recover the deflection produced by the bending moment. At the final phase, the stating tower is removed, and the bridge remain in this final position as seen in Fig. 3.

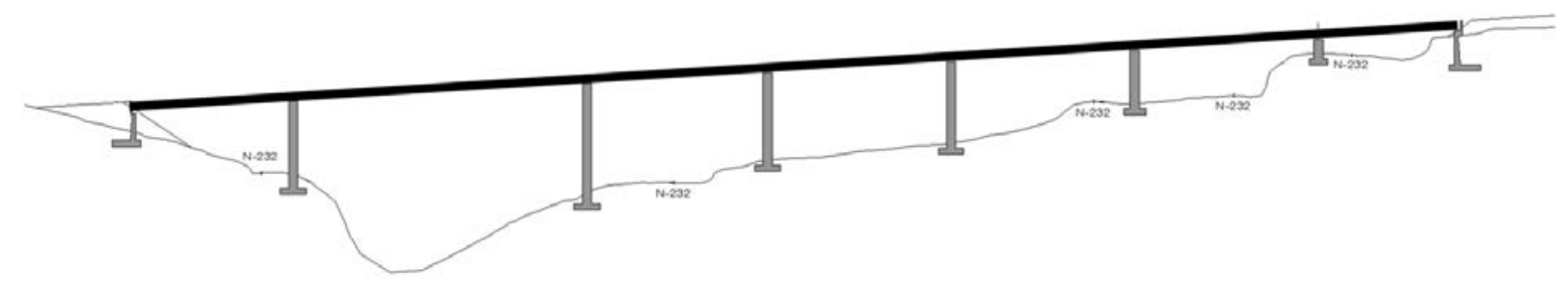

Figure 3. Box-girder bridge alternative

The second bridge alternative is to save the $100 \mathrm{~m}$ span length with a Bowstring bridge (Fig. 4). The deck is made with steel due to the functioning of the structural system that compresses the arch and tensions the deck, because of this, the tension capacity of the steel makes it the best material to conform the deck section. The constructive process consists in building the shorter span length sections and pushing the complete bowstring arch held by cranes arranged on the top of the end stack.

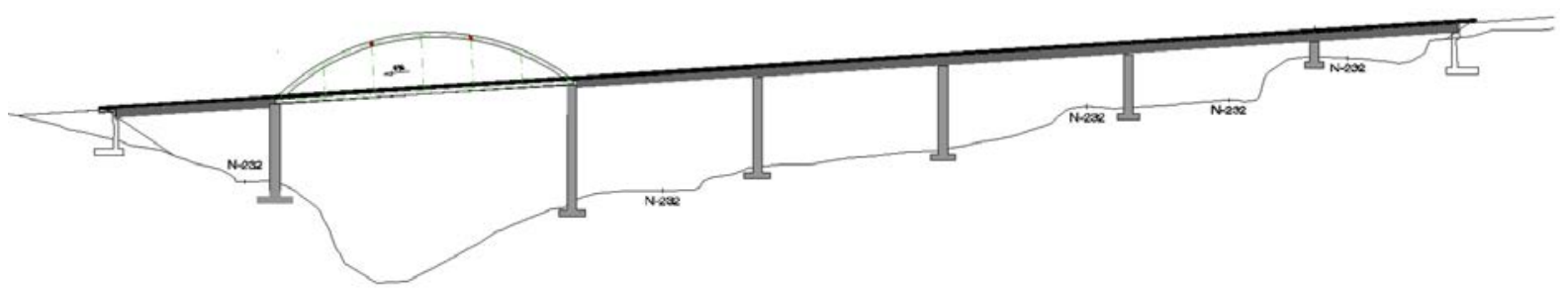

Figure 4. Bowstring bridge alternative

The third alternative is a low-arch bridge (Fig. 5), the constructions of the substructure allow to the deck to have an intermediate support reducing the span length to $100 \mathrm{~m}$ to half. The construction process starts with the construction of the lower-arch elements that subsequently are departed to join, forming the intermediate support, then the deck is pushed above the props. 


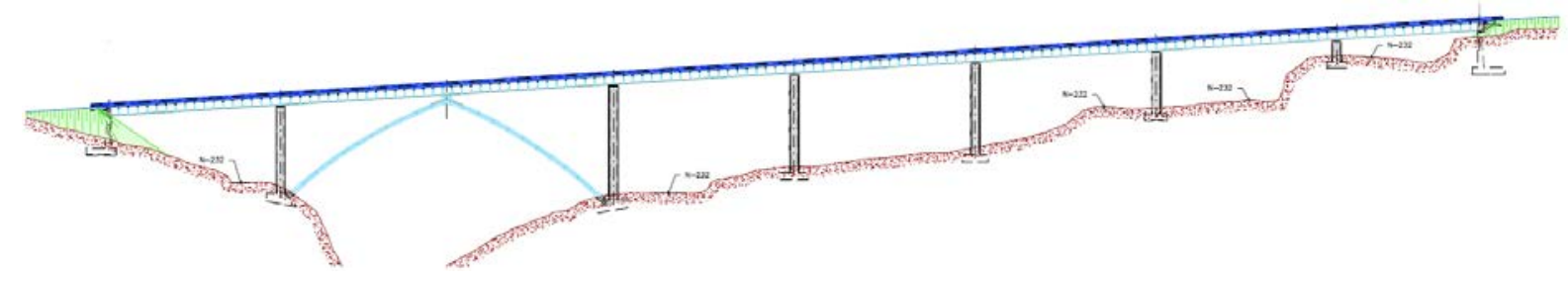

Figure 5. Lower arch bridge alternative

The last alternative is a cable-stayed bridge composed of a reinforced concrete pylon, on which seven pairs of stacks have been anchored. These stacks supports the steel deck that are constructed span by span in a progressive cantilever assembly.

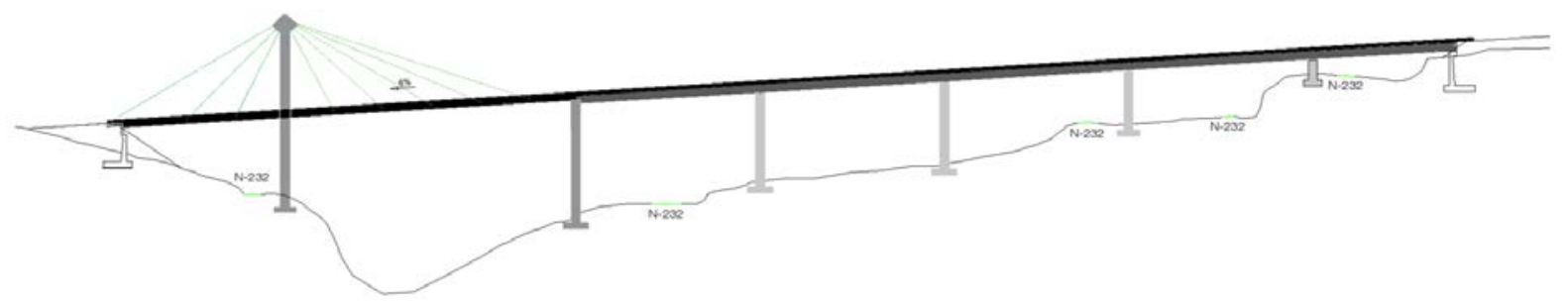

Figure 6. Cable stayed bridge alternative

\subsubsection{Selected criteria to the assessment}

The main criteria selected to the assessment of each of the alternatives have been chosen taking into account the three sustainability Indicators: Environmental, Social and Economic. The environmental indicator has been assessed directly, but the other two indicators have been assessed taking into account and evaluating other two sub-criteria for each one. The social criteria have been represented by the aesthetic and the necessity of conservation of the bridge, while the cost and the constructive ease have been assessed to obtain the economic sustainability indicator. The hierarchical structure of the criteria is showed in Fig. 7.

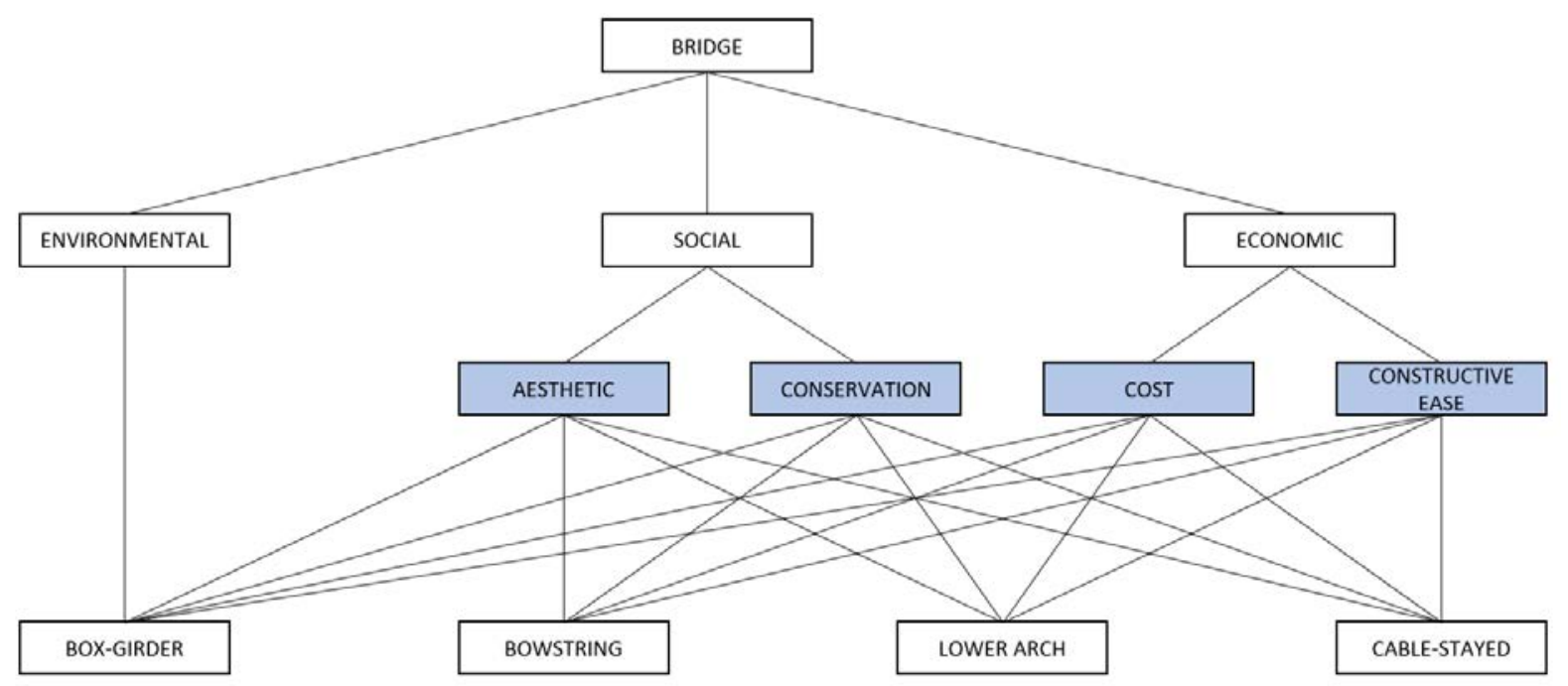

Figure 7. Selected criteria hierarchical structure

\section{RESULTS}

\subsection{Analytical Hierarchy Process (AHP)}

The four alternatives: Box-girder (BG), Bowstring (BS), Lower Arch (LA), Cable Stayed (CS) have been compared according to the different sub-criteria: Aesthetic $(A)$, Conservation $(C O)$, Cost $(C)$ and 
Constructive Ease (CE) to assess the main criteria: Environmental (E), Social (S) and Economic (EC) showed in Fig. 7.

The comparison matrix (CM) values and the eigenvectors obtained are shown below: (8) Main criteria, (9) Social Sub-criteria, (10) Economic sub-criteria, (11) Environmental sub-criteria, (12) Aesthetic, (13) Conservation, (14) Constructive Ease, and (15) Cost.

$$
\begin{aligned}
& \text { E } S \quad E C \\
& \underset{E C}{E}\left(\begin{array}{ccc}
1 & 3 & 1 / 3 \\
1 / 3 & 1 & 1 / 7 \\
3 & 7 & 1
\end{array}\right)=\left(\begin{array}{l}
0.2426 \\
0.0879 \\
0.6694
\end{array}\right) \\
& \underset{C O}{A}\left(\begin{array}{cc}
1 & 1 / 3 \\
3 & 1
\end{array}\right)=\left(\begin{array}{l}
0.2500 \\
0.7500
\end{array}\right) \\
& \text { C CE }
\end{aligned}
$$

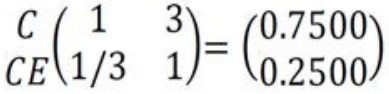

$$
\begin{aligned}
& B G \quad B S \quad L A \quad C S \\
& \begin{array}{l}
B G \\
B S \\
L A \\
C S
\end{array} \quad\left(\begin{array}{cccc}
1 & 7 & 7 & 5 \\
1 / 7 & 1 & 1 & 1 / 3 \\
1 / 5 & 3 & 3 & 1 / 3 \\
1 / 3
\end{array}\right)=\left(\begin{array}{l}
0.6541 \\
0.0772 \\
0.0772 \\
0.1915
\end{array}\right) \\
& B G \quad B S \quad L A \quad C S \\
& \begin{array}{l}
B G \\
B S \\
L A \\
C S
\end{array} \quad\left(\begin{array}{cccc}
1 & 1 / 5 & 1 / 7 & 1 / 9 \\
5 & 1 & 1 / 3 & 1 / 5 \\
7 & 3 & 1 & 1 / 3 \\
9 & 5 & 3 & 1
\end{array}\right)=\left(\begin{array}{l}
0.0393 \\
0.1260 \\
0.2696 \\
0.5651
\end{array}\right) \\
& B G \quad B S \quad L A \quad C S \\
& \begin{array}{l}
B G \\
B S \\
L A \\
C S
\end{array} \quad\left(\begin{array}{cccc}
1 & 5 & 3 & 7 \\
1 / 5 & 1 & 1 / 3 & 5 \\
1 / 7 & 1 / 5 & 1 & 7 \\
1 / 7 & 1
\end{array}\right)=\left(\begin{array}{l}
0.5481 \\
0.1301 \\
0.2785 \\
0.0433
\end{array}\right) \\
& B G \quad B S \quad L A \quad C S \\
& \begin{array}{l}
B G \\
B S \\
L A \\
C S
\end{array} \quad\left(\begin{array}{cccc}
1 & 5 & 1 & 1 / 7 \\
1 & 1 & 1 / 3 & 1 / 9 \\
7 & 9 & 1 & 1 / 5
\end{array}\right)=\left(\begin{array}{l}
0.1458 \\
0.0465 \\
0.1396 \\
0.6681
\end{array}\right) \\
& \begin{array}{l}
B G \\
B S \\
L A \\
C S
\end{array}\left(\begin{array}{l}
4,165,267.73 \\
4,379,966.64 \\
4,683,410.74
\end{array}\right)=\left(\begin{array}{l}
0.2647 \\
0.2517 \\
0.2482 \\
0.2354
\end{array}\right)
\end{aligned}
$$

The cost eigenvector has been obtained directly, because is an objective criterion. To obtain the weighting of each alternative value, they have been divided by the sum of the inverse of all alternatives. Once the values of the weights are obtained for each alternative for each criteria (11-15), these values are multiplied by the weighting of the criteria (8-10). 


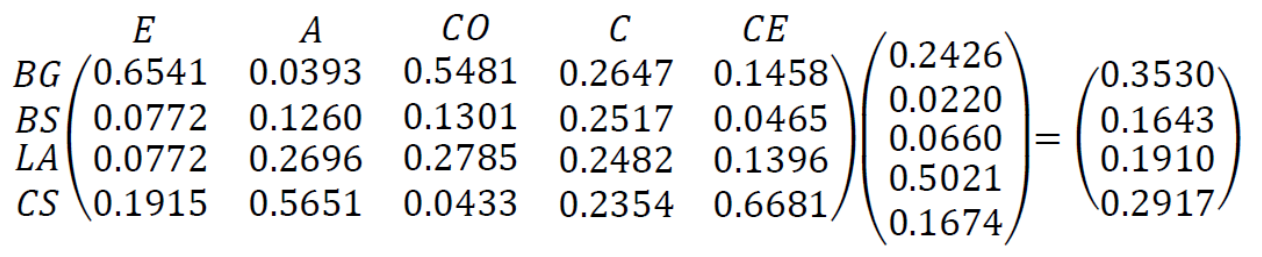

The BG alternative has obtained the highest score with a 0.3530 score and it is the best alternative according to this decision-making method (15).

\subsection{Simple Additive Weighting (SAW)}

To carry out the SAW method, the punctuation values for each alternative according to each criterion and the sub-criteria weighting have been obtained with the AHP method comparison, because of its ability to transform subjective values into objective ones for their assessment.

Table 2. SAW method summary

\begin{tabular}{|c|c|c|c|c|c|c|c|}
\hline \multirow[b]{2}{*}{ Criteria } & \multirow[b]{2}{*}{$\max / \min$} & \multirow[b]{2}{*}{ Optimum } & \multirow[b]{2}{*}{ Weight } & \multicolumn{4}{|c|}{ Alternatives } \\
\hline & & & & BG & BS & LA & CS \\
\hline$E$ & $\max$ & 0.6541 & 0.2426 & 0.6541 & 0.0772 & 0.0772 & 0.1915 \\
\hline A & $\max$ & 0.5651 & 0.0220 & 0.0393 & 0.1260 & 0.2696 & 0.5651 \\
\hline $\mathrm{CO}$ & $\max$ & 0.5481 & 0.0660 & 0.5481 & 0.1301 & 0.2785 & 0.0433 \\
\hline C & $\min$ & $4,165,267.73$ & 0.5021 & $4,165,267.73$ & $4,379,966.64$ & $4,442,678.10$ & $4,683,410.74$ \\
\hline CE & $\max$ & 0.6681 & 0.1674 & 0.1458 & 0.0465 & 0.1396 & 0.6681 \\
\hline & & Score & & 0.8487 & 0.5383 & 0.5783 & 0.7121 \\
\hline
\end{tabular}

As it is shown in Tab. 2 the BG alternative has obtained a score of 0.8487 and it is the best alternative according to this decision-making method.

\subsection{Method comparison}

The selected alternative for both methods is the BG bridge, and the differences obtained between the assessment of both methods are small, but the difference between the four alternatives is accentuated by the AHP method.

Table 3. Worsening percentage in SAW and AHP method

\begin{tabular}{ccc}
\hline Alternatives & SAW & AHP \\
\hline BG & $0.00 \%$ & $0.00 \%$ \\
BS & $36.57 \%$ & $53.47 \%$ \\
LA & $31.86 \%$ & $45.90 \%$ \\
CS & $16.10 \%$ & $17.36 \%$ \\
\hline
\end{tabular}

\section{CONCLUSIONS}

This paper has described how decision-making methods allow the engineers to take the best decision according to different criteria, evaluating their importance and weighting them in accordance. That knowledge is included in the subject called predictive and optimization models for concrete structures that belongs to the MSc course of concrete engineering of the Polytechnic University of Valencia. In that course many decision-making methods are introduced to the students, but in this work we have focused on two: Simple Additive Weighting (SAW) and Analytical Hierarchy Process (AHP), a direct comparison method and a pairwise comparison one respectively. The comparison between four different structural systems and construction methods have been done, obtaining the box-girder bridge the highest score with the two methods. Furthermore, the comparison between the two decision- 
making procedures used have been studied giving the student, not only the ability of using that methods, but also the implications and differences between them. This study sensitizes the MSc student with the importance of the decision-making processes in their professional toolpath and the possibilities to assess the alternatives for obtaining the best one according to the importance of each criteria.

\section{ACKNOWLEDGEMENTS}

The authors acknowledge the support for the Ministry of Economy and Company and FEDER funding (Project BIA2017-85098-R).

\section{REFERENCES}

[1] V. Yepes, E. Pellicer, and A. J. Ortega, "Designing a Benchmark Indicator for Managerial Competences in Construction at the Graduate Level," J. Prof. Issues Eng. Educ. Pract., vol. 138, no. 1, pp. 48-54, 2012.

[2] C. Torres-Machí, A. Carrión, V. Yepes, and E. Pellicer, "Employability of Graduate Students in Construction Management," J. Prof. Issues Eng. Educ. Pract., vol. 139, no. 2, pp. 163-170, 2013.

[3] T. García-Segura, V. Yepes, J. Alcalá, and E. Pérez-López, "Hybrid harmony search for sustainable design of post-tensioned concrete box-girder pedestrian bridges," Eng. Struct., vol. 92, pp. 112-122, 2015.

[4] E. Pellicer, L. A. Sierra, and V. Yepes, "Appraisal of infrastructure sustainability by graduate students using an active-learning method," J. Clean. Prod., vol. 113, pp. 884-896, 2016.

[5] T. García-Segura and V. Yepes, "Multiobjective optimization of post-tensioned concrete box-girder road bridges considering cost, CO2 emissions, and safety," Eng. Struct., vol. 125, pp. 325-336, 2016.

[6] V. Martí, T. García-Segura, and V. Yepes, "Structural design of precast-prestressed concrete Ubeam road bridges based on embodied energy," J. Clean. Prod., vol. 120, pp. 231-240, 2016.

[7] T. García-Segura, V. Yepes, and D. M. Frangopol, "Multi-objective design of post-tensioned concrete road bridges using artificial neural networks," Struct. Multidiscip. Optim., vol. 56, no. 1, pp. 139-150, 2017.

[8] T. García-Segura, V. Yepes, D.M. Frangopol, and D.Y. Yang, "Lifetime reliability-based optimization of post-tensioned box-girder bridges," Eng. Struct., vol. 145, pp. 381-391, 2017.

[9] P. Zastrow, F. Molina-Moreno, T. García-Segura, J. V. Martí, and V. Yepes, "Life cycle assessment of cost-optimized buttress earth-retaining walls: A parametric study," J. Clean. Prod., vol. 140, pp. 1037-1048, 2017.

[10] J. Salas and V. Yepes, "A discursive, many-objective approach for selecting more-evolved urban vulnerability assessment models," J. Clean. Prod., vol. 176, pp. 1231-1244, 2018.

[11] L. A. Sierra, V. Yepes, and E. Pellicer, "A review of multi-criteria assessment of the social sustainability of infrastructures," J. Clean. Prod., vol. 187, pp. 496-513, 2018.

[12] I. J. Navarro, J. V Martí, and V. Yepes, "Reliability-based maintenance optimization of corrosion preventive designs under a life cycle perspective," Environ. Impact Assess. Rev., vol. 74, pp. 2334, 2019.

[13] World Commission, "Report of the World Commission on Environment and Development: Our Common Future."

[14] C. Torres-Machi, V. Yepes, A. Chamorro, and E. Pellicer, "Current models and practices of economic and environmental evaluation for sustainable network-level pavement management," Revista de la Construccion, vol. 13, no. 2, pp. 49-56, 2014.

[15] H. Hasheminasab, Y. Gholipour, M. Kharrazi, and D. Streimikiene, "Life cycle approach in sustainability assessment for petroleum refinery projects with fuzzy-AHP," Energy Environ., vol. 29, no. 7, pp. 1208-1223, 2018. 
[16] L. F. Cabeza, L. Rincón, V. Vilariño, G. Pérez, and A. Castell, "Life cycle assessment (LCA) and life cycle energy analysis (LCEA) of buildings and the building sector: A review," Renew. Sustain. Energy Rev., vol. 29, pp. 394-416, 2014.

[17] L. A. Sierra, E. Pellicer, and V. Yepes, "Social Sustainability in the Lifecycle of Chilean Public Infrastructure," J. Constr. Eng. Manag., vol. 142, no. 5, p. 05015020, 2016.

[18] V. Penadés-Plà, T. García-Segura, J. V. Martí, and V. Yepes, "A review of multi-criteria decisionmaking methods applied to the sustainable bridge design," Sustainability, vol. 8, no. 12, p. 1295, 2016.

[19] D. Jato-Espino, E. Castillo-Lopez, J. Rodriguez-Hernandez, and J. C. Canteras-Jordana, "A review of application of multi-criteria decision making methods in construction," Autom. Constr., vol. 45, pp. 151-162, 2014.

[20] M. Bystrzanowska and M. Tobiszewski, "How can analysts use multicriteria decision analysis?," TrAC Trends Anal. Chem., vol. 105, pp. 98-105, 2018.

[21] J.-Z. Wu and G. Beliakov, "Nonadditivity index and capacity identification method in the context of multicriteria decision making," Inf. Sci. (Ny)., vol. 467, pp. 398-406, 2018.

[22] L. Rodríguez-Sinobas, S. Zubelzu, S. Perales-Momparler, and S. Canogar, "Techniques and criteria for sustainable urban stormwater management. The case study of Valdebebas (Madrid, Spain)," J. Clean. Prod., vol. 172, pp. 402-416, 2018.

[23] C.-S. Chen, Y.-H. Chiu, and L. Tsai, "Evaluating the adaptive reuse of historic buildings through multicriteria decision-making," Habitat Int., vol. 81, pp. 12-23, Nov. 2018.

[24] H. Wang, L. Duanmu, R. Lahdelma, and X. Li, "Developing a multicriteria decision support framework for CHP based combined district heating systems," Appl. Energy, vol. 205, pp. 345368, Nov. 2017.

[25] A. M. A. Bahurmoz, "The Analytic Hierarchy Process: A Methodology for Win-Win Management," 2006.

[26] R. W. Saaty, "The analytic hierarchy process-what it is and how it is used," Math. Model., vol. 9, no. 3-5, pp. 161-176, 1987.

[27] V. Motuziene, A. Rogoža, V. Lapinskiene, and T. Vilutiene, "Construction solutions for energy efficient single-family house based on its life cycle multi-criteria analysis: A case study," J. Clean. Prod., vol. 112, pp. 532-541, 2016.

[28] R. O. Parreiras et al., "A flexible multicriteria decision-making methodology to support the strategic management of Science, Technology and Innovation research funding programs," Eur. J. Oper. Res., vol. 272, no. 2, pp. 725-739, 2019.

[29] E. K. Zavadskas, Z. Turskis, and S. Kildiene, "State of art surveys of overviews on MCDM/MADM methods," Technol. Econ. Dev. Econ., vol. 20, no. 1, pp. 165-179, 2014.

[30] I. Lipuscek, M. Bohanec, L. Oblak, and L. Z. Zadnik Stirn, "A multi-criteria decisionmaking model for classifying wood products with respect to their impact on environment.," Int. J. Life Cycle Assess., vol. 15, no. 4, pp. 359-367, 2010.

[31] J. P. Basbagill, F. L. Flager, and M. Lepech, "A multi-objective feedback approach for evaluating sequential conceptual building design decisions," Autom. Constr., vol. 45, pp. 136-150, 2014.

[32] B. G. Hermann, C. Kroeze, and W. Jawjit, "Assessing environmental performance by combining life cycle assessment, multi-criteria analysis and environmental performance indicators," J. Clean. Prod., vol. 15, no. 18, pp. 1787-1796, 2007.

[33] G. A. Miller, "The magical number seven, plus or minus two: Some limits on our capacity for processing information," Psychol. Rev., vol. 101, no. 2, pp. 343-352, 1994.

[34] T. García-Segura, V. Penadés-Plà, and V. Yepes, "Sustainable bridge design by metamodelassisted multiobjective optimization and decision-making under uncertainty," J. Clean. Prod., vol. 202, pp. 904-915, 2018.

[35] D. Martínez-Muñoz, "Diseño estructural del tramo I del viaducto sobre el barranco de la Bota en la variante de la N-232 (T.M. de Morella, Castellón). Diseño Estructural," 2018. 